\title{
ISTRAŽIVANJE DOMINANTNIH STILOVA LIDERSTVA PRIMJENOM LIKERTOVOG MODELA U HOTELSKIM PREDUZEĆIMA
}

\author{
Spaso Kuzman \\ Fakultet za menadžment i poslovnu ekonomiju Univerziteta u Travniku, BIH
}

\begin{abstract}
:
Mnogi autori vođenje definišu kao sposobnost sticanja određenog položaja, a ne sposobnost zadobijanja sljedbenika. Zbog toga oni idu za položajem, višim rangom ili titulom, a kad to postignu, misle da su postali vođe. Takvo razmišljanje dovodi do dva uobičajena problema: oni koji imaju status vođe često su razočarani malim brojem sljedbenika, a oni koji nemaju takvu titulu, možda sebe ni ne vide kao vođu, pa zbog toga i ne razvijaju svoje sposobnosti vođenja. Svaka se ljudska djelatnost i aktivnost odvija sa određenim ciljem, i svako se konkretno istraživanje odvija sa određenim ciljem, a to je rasvjetljavanje problema koji je definisan kao predmet istraživanja. Neke odgovore na važna pitanja nećemo pronaći u literaturi, pa je zbog toga potrebno istraživati, utvrditi i pronaći odgovore za njih. Cilj ovog rada je primjeniti i razviti metodologiju Rensisa Likerta sa ciljem utvrđivanja dominantnih stilova liderstva u hotelskim preduzećima Bosne i Hercegovine.
\end{abstract}

\section{Key words:}

liderstvo,

stilovi, upravljanje, menadžeri, lideri.

\section{UVOD}

Vođstvo firme je veoma važan faktor organizacione uspješnosti jedan od najvažnijih aspekata menadžmenta..U svakom preduzeću postoje ljudi, a posao menadžera je da rade sa ljudima i da uz pomoć ljudi postignu njegove ciljeve. To je menadžerska funkcija vođenja. Vođenje je jedan važan aspekt menadžerskog posla, ali ne i sav posao menadžera. To je samo jedna od pet funkcija menadžera, pa je samim time uži pojam od menadžmenta. Međutim, vođenje je centralna i najvažnija funkcija menadžmenta i temeljni posao menadžera, čiji su sastavni dijelovi vođenje i vodstvo, motivacija za rad i motivisanje te komuniciranje u preduzeću.

Liderstvo kao proces znači da on nije karakteristika ili obilježje, nego uzajamni proces koji se odvija između lidera i njegovih sljedbenika. [8, str. 1] Uzajamni proces podrazumijeva da vođa utiče na sljedbenike, ali da je, također, i on sam pod uticajem sljedbenika. Definisano na ovaj način liderstvo je dostupno svima, a ne samo pojedincima koji posjeduju određene karakteristike. Liderstvo inkorporira uticaj i bavi se time kako pojedinac utiče na sljedbenike. Liderstvo bez uticaja ne postoji. Ono se javlja u grupi i uključuje uticaj na grupe pojedinaca koji imaju zajednički cilj. Lideri fokusiraju svoju energiju ka pojedincima koji pokušavaju da ostvare nešto zajedničkim snagama. [5, str. 85-90] Dakle, uspješan lider mora posjedovati znanja i sposobnosti da radi sa različitim aspektima motivacije, komunikacije, interpersonalnih veza, timskog rada i grupne dinamike. U uslovima brzih tehnoloških promjena, sve većih pritisaka globalne konkurencije, vođa mora da ima viziju, da okupi i motiviše druge ljude da rade na nekom poslu, da bude sposoban da identifikuje barijere i da radi na njivom otklanjanju.

Moderna istraživanja o vodstvu stavljaju akcenat na 3E: [9]

- Empowering (delegiranje dijela moći na članove organizacije predueća),

- Encouraging (ohrabrivanje članova organizacije preduzeća),

- Enabling (omogućavanje članovima organizacije da dostignu svoj puni potencijal).

Vodstvo treba da bude usmjereno na: izvršavanje zadataka pomoću pojedinaca i grupa, odnosno na ispunjenje potreba i očekivanja pojedinaca i grupa. $U$ tom smislu efektivno i efikasno vodstvo treba istovremeno ispunjavati tri međusobno povezane potrebe, i to: [1, str. 259-260] 
a) Potrebe posla (koji se mora izvršiti). Treba planirati, rasporediti zaduženja, postaviti ciljeve pojedincima, postaviti standarde, sistemski vrednovati učinke članova grupe, odnosno težiti ostvarenju ciljeva grupe ili će izgubiti njeno povjerenje, što će za posljedicu imati frustraciju i razočarenje članova, kritikovanje vođe, te nerijetko i raspad same grupe.

b) Potrebe grupe, odnose se na timski duh i moral (održavanje grupe putem efikasne komunikacije, disciplinskih i drugih mjera za pospješivanje timskog rada). Vođe nameću disciplinu kako bi spriječili nanošenje štete ukupnim naporima grupe. Vođe bi morale predstavljati uzor, sami ne bi smjeli kršiti pravila, te ne bi smjeli favorizovati jedne ili pak nametati nerazumne obaveze drugim članovima grupe.

c) Individualne potrebe članova grupe zahtjevaju da vođa mora otkriti šta svaki član želi od grupe te kako se ove potrebe mogu zadovoljiti i stopiti u zahtjev grupe.

Navedene grupe potreba su međusobno povezane, jer aktivnosti na jednom području utiču i na ostala područja, a sadržaj njihovog posla će se mijenjati u skladu sa opštom situacijom, što ukazuje na kontigencijski karakter ovog pristupa.

Istraživač menadžmenta (sa Univerziteta Mičigen) Rensis Likert, vršio je više empirijskih istraživanja u uspješnim i neuspješnim preduzećima kako bi utvrdio karakteristike menadžmenta. Na ovim osnovama R. Likert [pogledati referencu 2, str. 524., prema: 7, str. 60-65] je razradio model stilova liderstva odnosno sistema menadžmenta, kako ih je on nazvao, koji se sastoji u sljedećem:

Sistem 1: Eksploatatorski-autokratski, u kojem menadžer: ne pokazuje povjerenje u podređene, nameće odluke, nikada ne delegira, motiviše prijetnjama, malo komunicira i ne radi timski.

Sistem 2: Blagonaklono-autokratski (benevolentno autoritativni) u kojem menadžer: pokazuje površno i veoma malo povjerenje u podređene, nameće odluke, nikada ne delegira, motiviše nagrađivanjem, ponekad uključuje podređene u rješavanje problema.

Sistem 3: Konsultativni stil, u kojem menadžer: ne vjeruje $\mathrm{u}$ potpunosti u svoje podređene sluša podređene, ali kontroliše donošenje odluka motiviše nagradama i ponekad uključivanjem podređenih na konstruktivan način koristi ideje i mišljenja podređenih.

Sistem 4: Participativni, u kojem menadžer: u potpunosti vjeruje svojim podređenim dozvoljava im da sami donose odluke, motiviše nagrađivanjem za dostignute ciljeve koje su sami postavili dijeli ideje i mišljenja.

R. Likert [7] je razvio instrumente kako bi pospješio analizu o ponašanju uspješnih i neuspješnih preduzeća koji su omogućili zaposlenim, a i liderstvu, da promijene svoje preduzeće.

Ti instrumenti omogućili su utvrđivanje razlika između 4 navedena stila liderstva, a koje su determinisane slijedećim karakteristikama: [3, str. 12]

- motivacija,

- komunikacija,
- interakcija,

- donošenje odluka,

- uspostavljanje ciljeva,

- kontrola.

Kompleksan instrumentarij uključuje više od 20 takvih karakteristika. Likertov instrumentarij za analizu stila vođenja temelji se na prikupljanju stavova menadžera preko upitnika o osnovnim karakteristikama vođenja koji se odnose na pojedine varijable, prema kojima je Likert definisao svoja 4 stila vođenja. Te se varijable odnose na način kako menadžer radi s drugim ljudima, te s obzirom na svoju vrijednost, ukazuju na stil vođenja koji menadžer primjenjuje. Cjelovit pregled [za cjeloviti pregled ovih karakteristika pogledajte 6 , str. 75] navedenih karakteristika prikazan je slijedećoj tabeli (tabeli 1).

\section{METODOLOGIJA ISTRAŽIVANJA}

Kod prikupljanja podataka za mjerenje definisanih varijabli istraživanja, korištena je tehnika anonimnog anketnog upitnika metodom uzorka u hotelskim preduzećima iz Bosne i Hercegovine. Većina ispitanika nije pokazala razumijevanja ni vremena za sprovođenje anketnog upitnika, međutim, zahvaljujući pojedinim hotelima, nakon što su pokazali razumijevanje, odvojili potrebno vrijeme za anketiranje i samim tim mnogo pomogli u završnici ovog rada. Sa svakim od navedenih ispitanika, obavljen je kratak uvodni razgovor o anketnom upitniku. Napomenuto je da se radi o anonimnom upitniku koji neće ugroziti njihovu anonimnost, niti ugled hotela koje vodi. Ipak, insistirali su na anonimnosti i kodnom imenu što im je i dodijeljeno. Dalje, upitnik sadrži pet grupa pitanja koja su razvrstana u 20 pitanja. Ispitanici unaprijed imaju ponuđene odgovore na koje će zavisno o svojim stavovima i mišljenjima koja se odnose na zadanu temu izabrati određeni odgovor.

\section{REZULTATI ISTRAŽIVANJA}

Analizom efekata hotela izraženih kroz proizvodnost, apsentizam, fluktuaciju, zadovoljstvo i angažman zaposlenih dolazi se do zaključka da su efekti najniži u sistemu 1, a najviši u sistemu 4. Na temelju toga je moguće izvesti zaključak da je participativni stil liderstva najuspješniji pa se stoga i preporučuje u praktičnoj primjeni. Tako je na primjer, General Motors fabriku na području Atlante preveo iz sistema $2 \mathrm{u}$ sistem 4 . U periodu od tri godine poboljšala se direktna i indirektna efikasnost rada, poboljšao se kvalitet, smanjeni su troškovi, te stopa lomova alata, otpada i sl. [4, str. 375-379]

Grafički prikaz (slika 1.) takođe omogućava jednostavnu interpretaciju pojedinih aspekata rada menadžera $s$ drugim ljudima, tj. identifikaciju stilova funkcionisanja menadžmenta u okviru liderstva, motivisanja, komuniciranja, odlučivanja, postavljanja ciljeva i kontrolisanja.

Pošto Likert tvrdi kako su najuspješnija preduzeća ona čiji menadžeri primjenjuju stil 4 (participativni stil), to se u praktičnom smislu ovakav prikaz stila liderstva može koristiti za identifikaciju načina na koji menadžeri hotela 
obuhvaćenim istraživanjem obavljaju poslove vezane uz ljude, ali i za usmjeravanje menadžera prema najefikasnijim načinima obavljanja tih poslova.

Menadžeri srednjeg nivoa, u posmatranim hotelima, su rangirali po važnosti (na likertovoj skali) 20 karakteristika - pitanja, koje po svojoj srodnosti možemo svrstati u šest grupa, a to su: vodstvo (u užem smislu), motivacija, komuniciranje, odlučivanje, ciljevi i kontrola.

Prosječan stil je Sistem 3: Konsultativni stil, u kojem menadžer: ne vjeruje u potpunosti u svoje podređene sluša podređene, ali kontroliše donošenje odluka motiviše nagradama i ponekad uključivanjem podređenih na konstruktivan način koristi ideje i mišljenja podređenih.
Stavovi menadžera, u posmatranim hotelima, se ne razlikuju značajno prilikom analize vodstva (prve tri karakteristike), što se prvenstvano odnosi na povjerenje i slobodu komuniciranja prema podređenima.

Detaljnija analiza ovih karakteristika ukazuje na to da se prosječni rezultati po hotelima malo razlikuju međusobno (malo bolji rezultat je zabilježen u hotelu A-1), što se ne može reći za korištenje ideja podređenih (treće pitanje), gdje po prosječnom rangu prednjači hotel A-2 (najbolji stavovi menadžera srednjeg nivoa). Analiza pitanja koja se odnose na motivaciju nam govori da između zaposlenih menadžera srednjeg nivoa u našim hotelima nije prisutna velika razlika. Odgovori su prilično ujedna-

TABELA 1. LIKERTOVI STILOVI LIDERSTVA ${ }^{1}$

\begin{tabular}{|c|c|c|c|c|}
\hline KARAKTERISTIKE & SISTEM 1 & SISTEM 2 & SISTEM 3 & SISTEM 4 \\
\hline $\begin{array}{l}\text { Motivacija } \\
\text { vrste motiva } \\
\text { faktori motivacije } \\
\text { 1. strah, } \\
\text { 2. prijetnja, } \\
\text { 3. kazne, } \\
\text { 4. nagrade i } \\
\text { 5. participacija } \\
\text { stavovi prema preduzeću i } \\
\text { ciljevima } \\
\text { odgovornost za ostvarenje } \\
\text { ciljeva preduzeća }\end{array}$ & $\begin{array}{l}\text { ekonomski } \\
\text { 1, 2, 3, rijetko } 4 . \\
\text { neprijateljski, su- } \\
\text { protni } \\
\text { na vrhu }\end{array}$ & $\begin{array}{l}\text { ekonomski,socijalni } \\
3 \text { i } 4\end{array}$ & $\begin{array}{l}\text { ekonomski,socijalni, } \\
\text { ego } \\
4 \text {, nekad } 3 \text { i } 5\end{array}$ & $\begin{array}{l}\text { raznovrsni } \\
5,4, \text { zasnovano na } \\
\text { grupi }\end{array}$ \\
\hline $\begin{array}{l}\text { Komunikacija } \\
\text { smjer informacija } \\
\text { prihvaćanje informacija odozgo } \\
\text { tačnost informacija prema gore } \\
\text { informisanje menadžera o } \\
\text { problemima }\end{array}$ & $\begin{array}{l}\text { odozgo-dolje } \\
\text { s nepovjerenjem } \\
\text { krive } \\
\text { vrlo malo }\end{array}$ & $\begin{array}{l}\text { uglavnom prema } \\
\text { dolje } \\
\text { dosta nepovjerenja } \\
\text { cenzurisane } \\
\text { donekle }\end{array}$ & $\begin{array}{l}\text { dolje i gore } \\
\text { sumnja } \\
\text { selekcionisane } \\
\text { dosta dobra }\end{array}$ & $\begin{array}{l}\text { svestrane } \\
\text { povjerenje } \\
\text { tačne } \\
\text { potpune }\end{array}$ \\
\hline $\begin{array}{l}\text { Interakcija } \\
\text { količina i karakter } \\
\text { timski rad i saradnja } \\
\text { traženje ideja i saglasnost } \\
\text { zaposlenih } \\
\text { količina uticaja podređenih }\end{array}$ & $\begin{array}{l}\text { malo, s nepovjer- } \\
\text { enjem } \\
\text { nema } \\
\text { nema } \\
\text { nikakav }\end{array}$ & $\begin{array}{l}\text { malo s oprezom } \\
\text { malo } \\
\text { rijetko } \\
\text { vrlo mali }\end{array}$ & $\begin{array}{l}\text { prilično, s dosta } \\
\text { povjerenja } \\
\text { prilično } \\
\text { obično } \\
\text { dosta }\end{array}$ & $\begin{array}{l}\text { intenzivna, s povjer- } \\
\text { enjem } \\
\text { veliki } \\
\text { uvijek } \\
\text { veliki }\end{array}$ \\
\hline $\begin{array}{l}\text { Odlučivanje } \\
\text { nivo donošenja odluka } \\
\text { uključenost podređenih u } \\
\text { odlučivanje } \\
\text { decentralizacija odlučivanja } \\
\text { adekvatnost informisanja za } \\
\text { odlučivanje }\end{array}$ & $\begin{array}{l}\text { vrh } \\
\text { nema } \\
\text { nema } \\
\text { rijetka }\end{array}$ & $\begin{array}{l}\text { glavne odluke na } \\
\text { vrhu } \\
\text { povremeno } \\
\text { nema } \\
\text { ponekad }\end{array}$ & $\begin{array}{l}\text { okvirne na vrhu } \\
\text { konsultovanje } \\
\text { dosta } \\
\text { često }\end{array}$ & $\begin{array}{l}\text { na svim nivoima } \\
\text { potpuna } \\
\text { potpuna } \\
\text { uvijek }\end{array}$ \\
\hline $\begin{array}{l}\text { Ciljevi } \\
\text { način postavljanja } \\
\text { nivo postavljanja } \\
\text { otpor } \\
\text { analiza ciljeva i realizacije }\end{array}$ & $\begin{array}{l}\text { naredbe } \\
\text { vrh } \\
\text { jak } \\
\text { nikad }\end{array}$ & $\begin{array}{l}\text { ponekad rasprava } \\
\text { vrh } \\
\text { prilično } \\
\text { rijetko }\end{array}$ & $\begin{array}{l}\text { rasprava i naredbe } \\
\text { odjek } \\
\text { ponekad } \\
\text { polugodišnje }\end{array}$ & $\begin{array}{l}\text { grupno } \\
\text { područja } \\
\text { nema } \\
\text { mjesečno }\end{array}$ \\
\hline $\begin{array}{l}\text { Kontrola } \\
\text { interes za kontrolu } \\
\text { tačnost, mjerenje i informacija } \\
\text { koncentracija kontrole } \\
\text { neformalni otpori formalnoj } \\
\text { organizaciji } \\
\text { svrha upotrebe podataka }\end{array}$ & $\begin{array}{l}\text { vrh } \\
\text { tendencija iskriv- } \\
\text { ljenosti } \\
\text { na vrhu } \\
\text { uvijek } \\
\text { kažnjavanje }\end{array}$ & $\begin{array}{l}\text { vrh } \\
\text { često netačne } \\
\text { na vrhu, malo del- } \\
\text { egirana } \\
\text { obično } \\
\text { nagrade i kazne }\end{array}$ & $\begin{array}{l}\text { vrh i malo ostali } \\
\text { nivoi } \\
\text { djelimično tačne } \\
\text { dosta delegirana } \\
\text { ponekad } \\
\text { nagrade i samousm- } \\
\text { jerenje }\end{array}$ & $\begin{array}{l}\text { na svim nivoima } \\
\text { tačne } \\
\text { decentralizovana } \\
\text { nema } \\
\text { samoregulacija }\end{array}$ \\
\hline
\end{tabular}

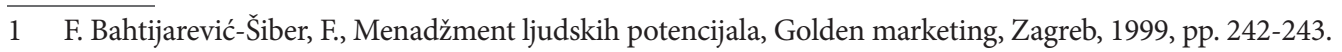


čeni iako je uočljivo da su impresije menadžera u hotelu A-3 karakteristične po malim odstupanjima u odnosu na ostatak uzorka.

Naime, u nekim karekteristikama (motivi za poticanje podređenih za izvršavanje radnih zadataka i postojanje timskog rada) pokazuju najlošiji rang, a u nekim najbolji (odgovornost za postizanje ciljeva preduzeća). Kada pominjemo slučajeve koji odstupaju od uobičajenih vrijednosti treba imati u vidu da je stav zaposlenih u hotelima A-4 i A-5 da postoje raznovrsniji oblici motivacije za rad u odnosu na ostale hotele (što nedvosmisleno potvrđuje prosječan rang na 5. pitanje).

Posmatrajući komunikaciju, kao karakteristiku izraženu kroz 4 pitanja, menadžeri u hotelu

A-5 su mišljenja da je ona raznovrsnija nego što to misle menadžeri u drugim hotelima, ali su istovremeno pokazali i najlošiji stepen razumjevanja problematike podređenih. Osim toga, razlike se javljaju i prilikom analize ostalih pitanja (gdje su, uglavnom, menadžeri iz hotela A-1 pokazali najveće zadovoljstvo). Odlučivanje na svim nivoima je najviše zastupljeno, po mišljenjima zaposlenih menadžera, u hotelima A-5 i A-4. Uključivanje podređenih u odlučivanje je u svim hotelima jednako i najčešće se radi o opštem konsultovanju, dok se ova mjera kao sredstvo motivacije najviše koristi u hotelu A-1.

Postavljanje ciljeva nije plod grupne akcije u posmatranom uzorku, jer se stavovi menadžera po ovom pitanju malo razlikuju i uglavnom se smatra da se prilikom postavljanja ciljeva prihvata nešto komentara ili nakon rasprave, ali dominiraju zapovijesti. Otpor radnika prema ciljevima je najizraženiji u hotelu A-3 i može se okarakterisati kao osrednji (60\% anketiranih se tako izjasnilo), dok u ostalim hotelima uglavnom smatraju da otpora nema ili je slab.

Na kraju, funkcija kontrole se u skoro svim hotelima obavlja značajno u upravi, dok se jedino za hotel A-1 može reći da je zastupljena na svim nivoima (80\% menadžera smatra da ovu funkciju obavljaju svi rukovodioci i zaposleni). Na pitanje o tome da li unutar organizacije postoji otpor gotovo da nema razlike u stavovima i svi

\begin{tabular}{|c|c|c|c|c|}
\hline Pitanja & Sistem 1 & Sistem 2 & Sistem 3 & Sistem 4 \\
\hline $\begin{array}{l}\text { VODSTVO (u užem smislu): } \\
\text { povjerenje prema podređenima } \\
\text { sloboda komuniciranja } \\
\text { korištenje ideja podređenih. } \\
\text { MOTIVACIJA: } \\
\text { motivi za poticanje podređenih za izvršavanje radnih zadataka } \\
\text { oblici motivacije za rad } \\
\text { odgovornost za postizanje ciljeva poduzeća } \\
\text { postojanje timskog rada. } \\
\text { KOMUNICIRANJE: } \\
\text { uobičajeni pravac toka informacija } \\
\text { prihvaćanje informacija odozgo } \\
\text { točnost informacija odozdo } \\
\text { poznavanje problematike podređenih. } \\
\text { ODLUČIVANJE: } \\
\text { nivo na kojem se donose odluke } \\
\text { uključivanje podređenih u donošenje odluka } \\
\text { korištenje uključivanja u donošenje odluka kao motivator } \\
\text { način postavljanja neposrednih rukovoditelja. } \\
\text { CILJEVI: } \\
\text { način postavljanja ciljeva poduzeća } \\
\text { otpor prema ciljevima od strane radnika. } \\
\text { KONTROLA: } \\
\text { gdje se obavlja funkcija kontrole } \\
\text { otpor pojedinaca i skupina menadžmentu } \\
\text { za što se koriste podaci o troškovima, proizvodnosti i drugi kontrolni podaci. } \\
\text { PROSJEČAN STIL: }\end{array}$ & & & & \\
\hline
\end{tabular}

2 Proračun autora. 
menadžeri su mišljenja da nema ovog problema ili je malo izražen. Homogenost nije prisutna i prilikom odgovora na poslednje pitanje - $\mathrm{u}$ koje svrhe se koriste kontrolni podaci? Većina menadžera smatra da je za nagrade, dok menadžeri u hotelu A-4 uglavnom (60\%) misle da je za samousmjeravanje zaposlenih, a u hotelu A-2 se smatra da je i za kazne (čak $60 \%$ ih je izabralo odgovor nagrade ili kazne).

\section{ZAKLJUČAK}

Vođenje predstavlja jednu veoma interesantnu temu. Istraživanja provedena do danas su veoma obimna i ne vidi se kraj istim. Na jednu ovakvu temu moglo bi se danima govoriti, kao i istraživati, analizirati, identifikovati. Zasigurno da je vođenje zauzelo snažnu poziciju u svijetu ekonomije, menadžmenta i biznisa te se nastavlja širiti i upotpunjavati. Na taj način konfrontiramo s vlastitim sumnjama i nadama. Mnogi autori konstatuju da postati lider nije jednostavno, ali da je to ipak mnogo lakše nego što to većina ljudi misli. Ukoliko se „okrenemo” i pogledamo svoj život unazad, svako od nas ne samo da posjeduje sposobnost vođenja nego zasigurno posjeduje i neko lidersko iskustvo u svom životu.

$\mathrm{Na}$ osnovu predhodno prezentovanog teoretskog dijela može se zaključiti da su uloga vođe, kao i odabir adekvatnog stila vođenja od presudnog značaja za uspješno poslovanje svakog preduzeća.Svaki vođa svojim sposobnostima, ličnim karakteristikama, znanjem i iskustvom, usmjerava i motiviše svoje zaposlene u svakodnevnim poslovima. U hotelima na prostoru $\mathrm{BiH}$, prema istraživanju koje je provedeno u svrhu ovog rada, može se zaključiti da dominira demokratsko-participativni stil.

Iz predhodnog se može zaključiti da vođe koje koriste demokratsko-participativni stil vodstva u svim situacijama imaju potpuno povjerenje u svoje podređene, uvijek konstruktivno koriste ideje i mišljenja podređenih. Likert je ustanovio da vođe koje koriste upravo ovaj stil vodstva imaju najviše uspjeha kao vođe.
Za razliku od demokratskog stila koji je već pomenut, mali procenat otpada na one hotele u kojima dominira autokratski stil vodstva. Istraživanjem se također došlo do zaključka, da upravo ovaj stil vodstva koriste vođe malih hotela sa veoma malim brojem neposredno podređenih osoba, kao i ukupnim brojem zaposlenih.

\section{LITERATURA}

[1] Bennis, W., Leadership theory and administrateive behavior: Th e problem of authority, Administrateive Science Quarterly, 4, 1959., str. 259-260.

[2] Buble, M., Menadžment, Ekonomski fakultet, Split, 2009, str. 524.,

[3] Buble, M., Poslovno vođenje, M.E.P. Consult, Zagreb, 2011., str. 12.

[4] Griffin, R. W.: Management, 8. Izd., Hougthon Mifflin Company, Boston, New York, 2005.,375-379.

[5] Kurtić, A., Kulović, Dž., Poslovno vođenje, Jordan studio: Centar za lično i profesionalno usavršavanje - CLPU, Sarajevo, 2011.

[6] Likert, R., Likert, G, J., New Ways of Managerial Confl icts, McGraw-Hill Book Company, New York, 1976.

[7] Likert, R., New Patterns of Managemant, McGraw-Hill Book Company, New York, 1961.

[8] Northouse, G. P., Leadership - Th eory and Practice, Sage Publications, Th ousand Oaks, California, 2004., str. 1.

[9] Northouse, P.G., Vodstvo: teorija i praksa, četvrto izdanje, Data status, Beograd, 2008.

\section{RESEARCH ON DOMINANT LEADERSHIP STYLES BY APPLYING LIKERT'S MODEL IN HOTEL ENTERPRISES}

\begin{abstract}
:
Many authors would rather define leadership as capability of gaining particular position, then as capability of gaining followers. Therefore, managerspursue the position, and when reached, they consider themselves as leaders. That way of thinking leads to two typical problems: those who are in the position of a leader are disappointed with small number of followers, while others who do not have that kind of position, don't consider themselves as leaders and therefore they do not develop their leadership skills. Every human activity takes place with defined objective and that is clarifying the problem that is defined as research subject. Research is necessary in order to find answers to some important questions that can not be found in the literature. Goal of this paper is to develop and apply methodology of Rensis Likert, in order to be able to define dominant leadership styles in hotel enterprises in Bosnia and Herzegovina.
\end{abstract}

\section{Key words:}

leadership, styles, management, managers, leaders. 